\title{
EFEKTIVITAS PELATIHAN "STRATEGI MENGAJAR SRL" DALAM MENINGKATKAN SELF-EFFICACY DAN SRL BELIEF GURU SD X
}

\author{
C. C. Mathilda V. Bolang ${ }^{1}$, Riana Sahrani ${ }^{2}$, Raja Oloan Tumanggor ${ }^{3}$ \\ ${ }^{1}$ Program Studi Magister Psikologi, Universitas Tarumanagara Jakarta \\ Email: mathilda.bolang@gmail.com \\ ${ }^{2}$ Program Studi Magister Psikologi, Universitas Tarumanagara Jakarta \\ Email: rianas@fpsi.untar.ac.id \\ ${ }^{3}$ Program Studi Magister Psikologi, Universitas Tarumanagara Jakarta \\ Email: raja@fpsi.untar.ac.id
}

\begin{abstract}
ABSTRAK
Penelitian ini bertujuan untuk mengetahui efektivitas pelatihan "Strategi Mengajar SRL" dalam meningkatkan selfefficacy dan SRL belief pada guru SD X yang menggunakan pendekatan instruksional student-centered, di mana keberhasilan pelatihan dilandaskan pada prinsip teori sosial-kognitif yaitu interaksi antara individu, lingkungan dan perilaku. Penelitian ini dilaksanakan pada bulan April-Mei 2017. Partisipan penelitian terdiri dari 7 guru sekolah dasar X yang dibagi ke dalam dua kelompok yaitu 4 guru pada kelompok eksperimen dan 3 lainnya pada kelompok kontrol. Jumlah partisipan dalam kelompok eksperimen terdiri dari 3 perempuan dan 1 laki-laki, serta 3 orang perempuan pada kelompok kontrol. Penelitian ini menggunakan desain penelitian eksperimental dengan pretest-posttest control group design. Instrumen pengumpulan data yang digunakan pada penelitian ini adalah Teacher's Self-Efficacy (TSE) (Schwarzer et al., 1999) dan Self-Regulated Learning Teacher's Belief (SRLTB) (Lombaerts et al., 2009). Data dianalisis dengan teknik paired sample t test dengan kriteria statistik non parametrik one sample Kolmogorov-Smirnov. Perhitungan dilakukan dengan membandingkan skor pretest dan posttest TSE dan SRLTB pada kelompok kontrol dan pada kelompok eksperimen. Berdasarkan perhitungan uji beda, didapatkan skor $t=-4,382$ dan $p=0,022$ ( $p<0,05$ ) pada teacher's self-efficacy kelompok eksperimen serta $t=-3,820$ dan $p=0,032$ pada SRL teacher's belief kelompok eksperimen. Hal ini menjelaskan bahwa hipotesis penelitian diterima, artinya pelatihan "Strategi Mengajar SRL” meningkatkan self-efficacy dan SRL belief guru SD X.
\end{abstract}

Keywords: teacher self-efficacy, SRL teachers belief, pelatihan “Strategi Mengajar SRL”, self-regulated learning, guru.

\section{PENDAhUluAN}

Penelitian di bidang psikologi pendidikan menunjukkan bahwa perubahan jaman abad 21 melahirkan kebutuhan akan kompetensi-kompetensi baru, sehingga dibutuhkan metode pendidikan yang baru yang mengharuskan guru mengubah paradigma mengenai metode pendidikan dan menyesuaikan keahlian praktik instruksionalnya dengan metode pengajaran yang baru (McCarthy, 2012). Self-regulated learning (SRL) disebutkan sebagai salah satu kompetensi terpenting siswa abad 21 dan membutuhkan peran penting guru dalam pembentukannya (Azevado et al., 2008). Self-regulated learning merujuk pada proses berupa siklus di mana pelajar secara personal mengaktivasi dan mempertahankan kognisi, afeksi dan perilaku yang secara sistematis mengarah kepada pencapaian tujuan-tujuan belajar (Schunk \& Zimmerman, 2012). Akan tetapi, mengajarkan SRL tidak mudah dan memiliki berbagai tantangan yang cukup sulit bahkan bagi guru yang sangat berpengalaman (Lombaerts et al., 2009). Walaupun sebuah institusi pendidikan sudah menggunakan pendekatan instruksional student-centered dan metode belajar aktif yang berdasarkan penelitian sesuai untuk menyediakan pengajaran SRL di kelas, namun pembelajaran SRL tidak akan terjadi jika guru tidak memberikan instruksi yang memang mendukung perkembangan keterampilan SRL (Zumbrunn et al., 2011). Hal ini diperkuat oleh Lombaerts et al. (2009), Endedijk (2015) serta Paris dan Winograd (dikutip Zumbrunn et al., 2011) bahwa walaupun sekolah sudah menggunakan kurikulum dengan pendekatan studentcentered, namun mengembangkan dan merencanakan pembelajaran yang dengan strategi-strategi yang dapat meningkatkan SRL siswa bukan suatu hal yang mudah untuk dilakukan oleh guru. 
SD X adalah salah satu unit dari sebuah institusi swasta yang bergerak di bidang pendidikan. Insititusi ini berdiri sejak 1996, menggunakan kurikulum dengan lisensi dari Amerika Serikat yang dikombinasikan dengan kurikulum Pendidikan Nasional. SD X sendiri berdiri pada tahun 2004. SD X menggunakan metode active learning, dengan pendekatan instruksional studentcentered, dengan tujuan akhir yaitu meluluskan para pemimpin yang dapat meregulasi diri sendiri (self-regulated leaders). Strategi belajar-mengajar sehari-hari di SD X dilandaskan pada teori konstruktivisme dan proses belajarnya sehari-hari menggunakan siklus SRL yang terdiri dari 3 fase yaitu planning, performance monitoring dan reflection (Sekolah X, 2012). Sekolah X sudah menyadari kendala berupa perubahan paradigma pada guru dan kendala dalam mengajarkan SRL di dalam kelas, sehingga sekolah $\mathrm{X}$ mengantisipasi dengan memberikan pelatihan bagi guru baru selama kurang lebih 2 bulan untuk memberikan informasi yang komprehensif mengenai kurikulum dan metode yang digunakan. Kepala sekolah juga diwajibkan melaksanakan observasi rutin dan memberikan intervensi berupa professional development rutin tiap 3 bulan dengan materi yang disesuaikan dengan kebutuhan guru pada saat itu.

Di SD X, khususnya program sekolah dasar (SD), ditemukan beberapa kejadian yang menunjukkan terjadinya inkonsistensi antara metode yang dianut sekolah dengan praktik mengajar (instruksional) guru di dalam kelas. Inkonsistensi antara lain seperti guru mengarahkan sepihak hal yang harus dilakukan siswa (directing) dan tidak memberikan kesempatan bagi siswa untuk mengutarakan dan menjalankan suatu kegiatan dengan memasukkan unsur minat atau idenya. Masih ditemukan juga di mana guru memerintahkan siswa untuk menyalin, bukannya mendorong siswa untuk menarik kesimpulan sendiri dan mengarahkan serta memberikan asistensi agar siswa dapat mengekspresikan kesimpulannya dengan tepat. Selain itu, beberapa kejadian menunjukkan bahwa guru tidak konsisten mengajarkan siswa untuk melakukan siklus SRL yang terdiri dari 3 fase yaitu planning, performance monitoring dan reflection, dalam proses belajar sehari-hari.

Berdasarkan identifikasi masalah awal dengan metode wawancara terhadap guru, ditemukan bahwa penyebab terjadinya inkonsistensi adalah self-efficacy guru dan SRL belief yang cenderung rendah. Teacher's self-efficacy adalah salah satu tipe dari self-efficacy yang diartikan sebagai sebuah ekspektasi/harapan yang situasional (bergantung pada situasi spesifik) atau keyakinan bahwa guru dapat membantu siswa belajar (Ashton \& Webb dikutip Erdem \& Demirel, 2007; Bandura dikutip Erdem \& Demirel, 2007). Teacher's self-efficacy memprediksikan bahwa guru dengan efficacy tinggi bekerja lebih keras dan bertahan lebih lama sekalipun siswanya sulit untuk diajarkan, sebab guru ini percaya kepada dirinya dan kepada siswanya (Woolfolk dikutip Erdem \& Demirel, 2017). Self-efficacy terbentuk dari 4 sumber, yaitu pengalaman-pengalaman penguasaan atau keberhasilan (mastery experiences), pengalaman-pengalaman tidak terduga (vicarious experiences) yang dihasilkan oleh orang lain (social modelling), pengaruh dari orang lain yang dipercaya atau sosok otoritas bagi seseorang (social persuasion) dan kondisi fisik serta emosi (physical and emotional states), di mana Mastery experiences sangat berpengaruh terhadap self-efficacy (Bandura dikutip Feist \& Feist, 2008).

Belief adalah suatu kondisi di mana seseorang menganggap sesuatu hal sebagai hal yang benar atau memungkinkan; memberikan kepercayaan terhadap seseorang atau sebuah gagasan; atau memberikan kepercayaan atau keyakinan terhadap sebuah kisah (Vallet, 2005). Belief terbentuk dari beberapa faktor, salah satunya adalah asosiasi seseorang terhadap karakteristik, kualitas dan atribut dari hal yang diyakini (Ajzen dan Fishbein, 1980). Self-regulated learning (SRL) belief merupakan bentuk spesifik dari belief yang merupakan keyakinan guru bahwa keterampilan SRL 
penting untuk diajarkan pada siswa. Berbagai peneliti berargumen bahwa pengetahuan dan keyakinan guru mengenai SRL memberikan dampak terhadap praktik belajar-mengajar di dalam kelas dan telah memicu disusunnya alat ukur kuantitatif dan kualitatif untuk mengevaluasi konstruk-konstruk ini (Lombaerts, DeBacker, Engels, van Braak, \& Athanasou; Wilson \& Bai dikutip Spruce \& Bol, 2015). Sebuah penelitian menemukan bahwa walaupun nilai-nilai positif pendekatan student-centered sudah sangat diketahui oleh kalangan pendidik, namun pendidik ternyata tidak berpegang pada nilai-nilai tersebut (Sablonniere et al., 2009). Penelitian lain menemukan bahwa guru tidak yakin tentang seberapa banyak dan jenis arahan apa yang dibutuhkan siswa untuk menjadi tuan dari pembelajarannya sendiri dan banyak pula guru yang masih menganggap bahwa mereka belum cukup siap untuk mengubah siswa menjadi selfregulated learners (Boekaerts; Zimmerman; Zimmerman \& Schunk; Perry \& Vandekamp dikutip Lombaerts, 2009).

Penelitian terbaru oleh Dignath (2016) meneliti tiga komponen yang menentukan apakah guru menerapkan pengajaran dengan strategi yang mendukung SRL siswa. Tiga komponen tersebut adalah belief, knowledge, dan self-efficacy. Penelitian ini membuahkan hasil bahwa self-efficacy merupakan faktor yang paling menentukan apakah guru akan memberikan pengajaran dengan strategi yang mendukung SRL, dibandingkan dengan belief dan knowledge guru. Dignath (2016) menyarankan bahwa penelitian selanjutnya sebaiknya melakukan intervensi berupa pelatihan guru yang dirancang sedemikian rupa agar dapat memberikan pengetahuan dan keterampilan pada guru tentang bagaimana menciptakan lingkungan belajar yang dapat membantu perkembangan SRL siswa. Dalam penelitian ini, penyebab inkonsistensi guru umumnya bukan pada kurangnya knowledge tentang filosofi dan metode mengajar SD X, sebab knowledge sudah diperoleh guru dari pelatihan wajib bagi guru baru. Sehingga, intervensi diberikan untuk meningkatkan self-efficacy dan SRL belief guru agar praktik mengajar di kelas sesuai dengan metode yang dianut, yaitu mengajarkan SRL pada siswa.

Pelatihan terbukti dapat meningkatkan self-efficacy dan belief. Penelitian Smith dan Day (2015) yang memberikan pelatihan Family Development Credential (FDC) berhasil meningkatkan selfefficacy para pekerja sosial. Ada pula penelitian Olsen dan kolega (2015) yang memberikan pelatihan Evidence Based Practice (EBP) yang berhasil meningkatkan EBP belief para instruktur klinis. Adapun, keberhasilan pelatihan "Strategi Mengajar SRL" dalam meningkatkan selfefficacy dan SRL belief guru merupakan penerapan dari teori sosial-kognitif dari Bandura (1986) yang menekankan pada reciprocal determinism, yaitu bahwa perilaku diatur dan ditentukan oleh individu melalui proses kognitif, dan oleh lingkungan melalui peristiwa-peristiwa yang merupakan stimulus eksternal sosial (Bandura, 1986). Pelatihan yang terdiri dari 8 sesi menyajikan pengetahuan dan informasi menggugah serta persuasif mengenai SRL dan strategi mengajarkan ketiga fase SRL, lalu dilanjutkan dengan praktik mengajar berupa role play dan simulation. Melalui pelatihan ini, guru memeroleh informasi positif mengenai karakteristik, kualitas dan atribut SRL untuk meningkatkan belief, social persuasion, social modelling dan mastery experience untuk meningkatkan self-efficacy, sehingga diharapkan self-efficacy dan belief guru meningkat.

Didukung oleh penelitian yang dilakukan oleh Smith dan Day (2015) serta Olsen dan kolega (2015), serta melanjutkan saran yang diberikan oleh Dignath et al. (2016), peneliti melakukan penelitian dengan hipotesis: pelatihan "Strategi Mengajar SRL" efektif dalam meningkatkan self-efficacy dan SRL belief guru SD X. 


\section{METODE PENELITIAN}

Partisipan diambil dari populasi guru SD di SD X. Peneliti mengambil partisipan sebanyak 7 orang guru, yaitu 4 guru pada kelompok eksperimen dan 3 guru pada kelompok kontrol. Berdasarkan jenis kelamin, jumlah partisipan laki-laki ada 1 orang $(14,3 \%)$ dan jumlah partisipan perempuan ada 6 orang $(85,7 \%)$. Penelitian menggunakan desain penelitian eksperimental dengan pretest-posttest control group design. Peneliti menggunakan tiga variabel yaitu Pelatihan Strategi Mengajar SRL, teacher's self-efficacy dan SRL teacher's belief. Peneliti menyebarkan kuesioner untuk diisi oleh partisipan. Teknik sampling yang digunakan dalam penelitian ini adalah convenience sampling karena penentuan sampel dari populasi guru SD X berdasarkan pertimbangan mengenai efisiensi, efektivitas, dan kemudahan peneliti. Teknik analisis yang digunakan adalah statistik deskriptif dan paired sample $t$ test. Teknik statistik deskriptif digunakan peneliti untuk memeroleh gambaran umum partisipan penelitian, memeroleh norma yang menggambarkan kategori teacher's self-efficacy dan SRL teacher's belief. Penyusunan norma menggunakan persentil 50\% batas bawah dan 50\% batas atas. Paired sample t-test digunakan untuk mengetahui apakah terjadi perubahan yang signifikan sebelum dan setelah perlakuan. Perlakuan yang diberikan berupa pelatihan sebanyak 8 pertemuan dalam periode 2 minggu bagi kelompok eksperimen dan berupa psikoedukasi dengan metode ceramah sebanyak 1 pertemuan bagi kelompok kontrol. Pengolahan data dimulai dengan melakukan input data kuesioner teacher's self-efficacy dan SRL teacher's belief, lalu dilanjutkan dengan melakukan uji normalitas one-sample Kolmogorov-Smirnov. Setelah uji normalitas terpenuhi, maka peneliti melakukan paired sample t-test.

Teacher's Self-Efficacy diukur dengan menggunakan alat ukur Teacher's Self-Efficacy. Butir yang digunakan sebanyak 10, yang terdiri dari empat sub-skala yaitu job accomplishment, skill development on the job, social interactions with students, parents and colleagues dan coping with job stress. Alat ukur Teacher's Self-Efficacy diciptakan oleh Schwarzer dan kolega pada tahun 1999. Contoh butir dari alat ukur Teacher's Self-Efficacy antara lain "Saya yakin dapat berhasil mengajarkan semua konten pelajaran, bahkan kepada siswa yang sangat sulit untuk diajarkan" (job accomplishment). Hasil uji reliabilitas dari teacher's self-efficacy terbukti dengan Cronbach's Alpha 0.915.

Belief guru terhadap SRL diukur dengan menggunakan alat ukur Self-Regulated Learning Teacher's Belief (SRLTB). Butir yang digunakan sebanyak 9. SRLTB dikembangkan dari tiga aspek yaitu sikap guru terhadap SRL, pengalaman pribadi dengan penerapan SRL dan keuntungan-kerugian serta kesulitan saat membuat/menyediakan pembelajaran yang mendukung keterampilan SRL. Alat ukur SRLTB diciptakan oleh Lombaerts dan kolega pada tahun (2009). Contoh butir dari alat ukur SRLTB antara lain "Siswa memiliki kemampuan untuk menentukan apa yang ingin mereka pelajari". Hasil uji reliabilitas dari SRLTB terbukti dengan Cronbach's Alpha 0.839 .

\section{HASIL DAN PEMBAHASAN}

Sebelum melakukan analisis paired sample $t$ test peneliti terlebih dahulu melakukan uji normalitas 1 sample kolmogorov-smirnov untuk mengetahui normal atau tidaknya sebaran data. Hasil uji normalitas menunjukkan bahwa sebaran data pretest dan posttest variabel teacher's self-efficacy dan SRL teacher's belief baik pada kelompok eksperimen maupun kelompok kontrol normal ( $\mathrm{p}>0.05)$, dengan rincian hasil seperti terlihat pada Tabel 1. 
Tabel 1. Hasil uji normalitas

\begin{tabular}{ccccccccc}
\hline & \multicolumn{3}{c}{ Kelompok Eksperimen } & \multicolumn{3}{c}{ Kelompok Kontrol } \\
\cline { 2 - 8 } & $\begin{array}{c}\text { Kolmogorov- } \\
\text { Smirnov Z }\end{array}$ & p (sig) & \multicolumn{1}{c}{$\begin{array}{c}\text { Kolmogorov- } \\
\text { Smirnov Z }\end{array}$} & p (sig) \\
\cline { 2 - 8 } & $\mathbf{1}$ & $\mathbf{2}$ & $\mathbf{1}$ & $\mathbf{2}$ & $\mathbf{1}$ & $\mathbf{2}$ & $\mathbf{1}$ & $\mathbf{2}$ \\
\hline $\begin{array}{c}\text { Alat Ukur } \\
\text { SRL Teacher's } \\
\text { Belief }\end{array}$ & 0,883 & 0,883 & 0,417 & 0,417 & 0,438 & 0,303 & 0,991 & 1,000 \\
\hline $\begin{array}{c}\text { Alat Ukur } \\
\text { Teacher's Self- } \\
\text { Efficacy }\end{array}$ & 0,797 & 0,734 & 0,550 & 0,655 & 0,303 & 0,478 & 1,000 & 0,976 \\
\hline Keterangan. 1 = sebelum perlakuan, 2 = sesudah perlakuan & & & & & & & \\
\hline
\end{tabular}

Setelah itu, peneliti membandingkan perolehan skor pretest dan posttest. Berdasarkan perbandingan mean empirik dan mean hipotetik pada skor pretest dan posttest kelompok eksperimen dan kelompok kontrol, diperoleh hasil bahwa mean empirik ketujuh partisipan sesudah pelatihan lebih besar dibandingkan mean hipotetik. Perbedaan mean empirik pada variabel teacher's self-efficay kelompok eksperimen juga dapat dilihat pada Grafik 1.

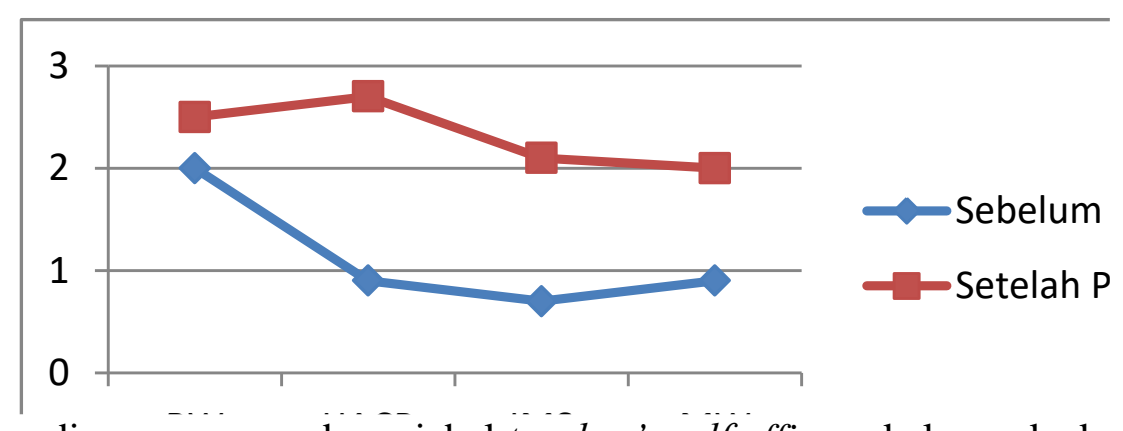

Grafik 1. Perbandingan mean pada variabel teacher's self-efficacy kelompok eksperimen (KE).

Perbandingan mean empirik pada variabel SRL teacher's belief kelompok eksperimen dapat dilihat pada Grafik 2.

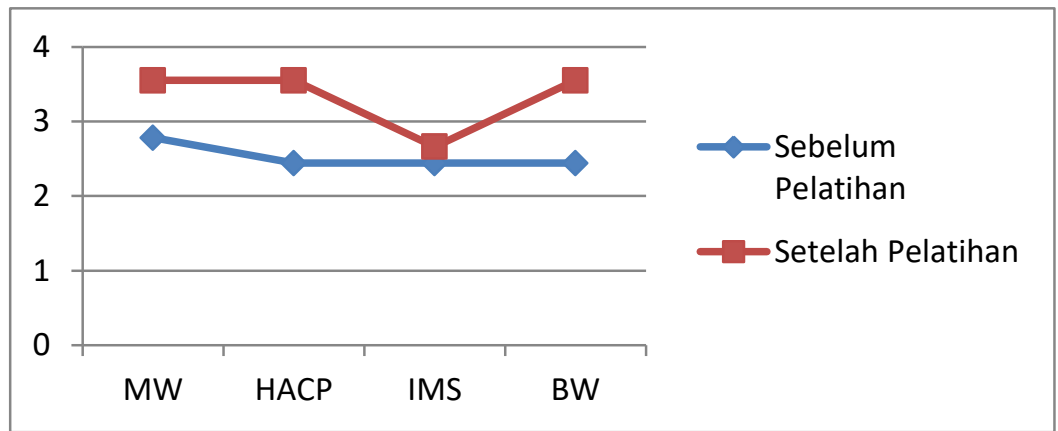

Grafik 2. Perbandingan mean pada variabel SRL teacher's kelompok eksperimen (KE).

Setelah membandingkan skor pretest dan posttest pada kedua variabel, peneliti lalu menganalisis data dengan menggunakan paired sample t test untuk mengetahui apakah terjadi perubahan yang signifikan sebelum dan setelah pelatihan. Pengujian menunjukkan hasil bahwa ada peningkatan signifikan pada variabel teacher's self-efficacy dan SRL teacher's belief. Skor t yang negatif menunjukkan adanya peningkatan setelah partisipan diberikan pelatihan. Signifikansi yang kurang dari 0,05 ( $\mathrm{p}<0,05)$ menunjukkan bahwa peningkatan yang terjadi tergolong signifikan setelah partisipan mendapatkan pelatihan. Hasil analisis menunjukkan bahwa pada kelompok eksperimen, pelatihan "Strategi Mengajar SRL" efektif meningkatkan TSE dan SRLTB secara signifikan, 
sedangkan pada kelompok kontrol psikoedukasi "Strategi Mengajar SRL" efektif meningkatkan TSE dan SRLTB, namun tidak signifikan pada variabel TSE. Hasil analisis paired sample t test secara rinci dapat dilihat di dalam tabel berikut.

Tabel 2. Analisis Paired Sample T-Test pada variabel Teacher's Self-Efficacy dan SRL Teacher's Belief Kelompok Eksperimen (KE) dan Kelompok Kontrol (KK)

\begin{tabular}{lllll}
\hline & KE & \multicolumn{3}{l}{ KK } \\
\hline & T & p (sig) & T & p (sig) \\
\hline Teacher's Self-Efficacy & $-4,382$ & 0,022 & $-4,158$ & 0,053 \\
SRL Teacher's Belief & $-3,820$ & 0,032 & $-4,421$ & 0,048 \\
\hline
\end{tabular}

\section{KESIMPULAN DAN DISKUSI}

Dalam penelitian kali ini ditemukan bahwa pelatihan "Strategi Mengajar SRL" efektif meningkatkan self-efficacy dan SRL belief guru SD X. Hal ini berarti bahwa pelatihan ini efektif meningkatkan keyakinan guru bahwa ia mampu membantu siswa belajar dengan efektif dengan cara menyampaikan konten pelajaran dengan baik, mempertahankan kelas yang teratur sehingga kondusif bagi pembelajaran, mendapatkan sumber-sumber dan keterlibatan orangtua dalam kegiatan belajar siswa, serta mampu menangkal pengaruh-pengaruh sosial yang dapat menurunkan komitmen belajar siswa. Pelatihan ini juga efektif meningkatkan keyakinan guru bahwa SRL adalah keterampilan yang sangat penting untuk dimiliki oleh siswa dan dapat meningkatkan performa siswa dalam berbagai aspek.

Hal ini sesuai dengan penelitian dari Smith dan Day (2015) yang memberikan pelatihan Family Development Credential (FDC) dan berhasil meningkatkan self-efficacy para pekerja social, serta penelitian Olsen dan kolega (2015) yang memberikan pelatihan Evidence Based Practice (EBP) dan berhasil meningkatkan EBP belief para instruktur klinis. Adapun, keberhasilan pelatihan "Strategi Mengajar SRL" dalam meningkatkan self-efficacy dan SRL belief guru merupakan penerapan dari teori sosial-kognitif dari Bandura (1986) yang menekankan pada reciprocal determinism, yaitu bahwa perilaku diatur dan ditentukan oleh individu melalui proses kognitif, dan oleh lingkungan melalui peristiwa-peristiwa yang merupakan stimulus eksternal sosial (Bandura, 1986). Dalam penelitian ini, perilaku diubah dengan cara menyajikan informasiinformasi dan dan melatih keterampilan-keterampilan mengajar yang baru (proses kognitif) di mana materi pelatihan berdasarkan pada teori tentang pembentuk self-efficacy dan belief. Untuk aspek lingkungan, pelatihan menyajikan informasi yang sifatnya persuasif dan testimonial, serta memberikan evaluasi atau umpan balik secara langsung baik dari pembicara pelatihan maupun dari sesama partisipan.

Pelatihan "Strategi Mengajar SRL" menyajikan pengetahuan dan keterampilan. Pengetahuan yang disajikan berupa konsep SRL, fase-fase SRL, serta strategi-strategi apa saja yang dapat digunakan guru untuk mengajarkan ketiga fase SRL kepada siswanya. Informasi lain yang disajikan juga berupa informasi yang memotivasi dan persuasif sehingga dapat menggugah. Hal ini sesuai dengan teori Ajzen dan Fishbein (1980) yang mengatakan bahwa keyakinan dapat dikuatkan atau diubah dengan cara memaparkan informasi positif mengenai karakteristik, kualitas dan atribut hal tersebut, dan juga dikuatkan oleh Kilbourne dan Pipher (2000) yang menyatakan bahwa keyakinan seseorang dapat terbentuk atau berubah melalui pemberian persuasi secara berulang. Bandura (dikutip Feist \& Feist, 2008) juga menyatakan bahwa salah satu pembentuk atau faktor yang dapat meningkatkan self-efficacy adalah social persuasion di mana self-efficacy seseorang dapat meningkat ketika mendapatkan persuasi dari orang lain atau 
dari sosok yang memiliki otoritas, serta social modelling yaitu pengalaman kesuksesan atau keberhasilan orang lain dalam melakukan suatu hal di mana orang lain yang menjadi model memiliki kompetensi yang kurang lebih sama dengan diri orang yang mengamati.

Keterampilan yang disajikan berupa praktik (simulasi dan role-play) mengajar mengunakan strategi-strategi mengajar yang tepat dalam mengajarkan ketiga fase SRL kepada siswa, dan mendapatkan umpan balik dari pembicara dan sesama partisipan. Hal ini dilandaskan pada teori Bandura (dikutip Feist \& Feist, 2008) yaitu self-efficacy terbentuk atau dapat ditingkatkan melalui mastery experience atau pemberian pengalaman keberhasilan atau penguasaan.

Temuan menarik dalam penelitian ini adalah bahwa Peningkatan SRL belief partisipan signifikan perbedaannya pada sebelum dan sesudah pelatihan, padahal Pajares (dikutip Dignath, 2016) mengatakan bahwa keyakinan merupakan hal yang sangat sulit untuk diubah. Hal ini disebabkan karena guru SD X pada dasarnya sudah menjalani metode pengajaran yang dilandaskan pada prinsip-prinsip SRL. Namun, selama ini tidak terpapar pada terminologi SRL itu sendiri, tidak dijelaskan mengapa harus mengajar menggunakan metode tersebut. Hal ini membuat mereka bertanya-tanya dan ragu dalam menjalankan metode tersebut, sebab merasa tidak yakin bahwa metode ini dapat berhasil dan mereka juga merasa tidak tahu bagaimana cara melakukan pengajaran dengan strategi yang tepat. Setelah digugah dan dipaparkan dengan informasi baru mengenai SRL, partisipan merasa bahwa dari pelatihan ini mereka memeroleh "benang merah" dari apa yang sudah mereka jalani selama ini. Hal ini juga sejalan dengan penemuan Postmus dan kolega (2013), yaitu bahwa pendidikan dan pelatihan dapat memengaruhi beberapa hal, salah satunya keyakinan individu.

Pada kelompok kontrol, hasil penelitian menunjukkan bahwa terdapat peningkatan yang signifikan pada skor SRL teacher's belief, sedangkan pada skor teacher's self-efficacy, skor meningkat namun tidak signifikan. Hal ini menunjukkan bahwa intervensi yang diberikan kepada kelompok kontrol berupa psikoedukasi tidak cukup efektif untuk meningkatkan keyakinan guru dalam melakukan pengajaran yang lebih baik, dalam hal ini dalam mengajarkan SRL, sebab kelompok kontrol tidak mengalami praktik mengajar menggunakan strategi-strategi mengajar SRL seperti yang dialami oleh partisipan kelompok eksperimen, padahal sesuai dengan teori, self-efficacy terbentuk atau dapat ditingkatkan melalui mastery experience atau pemberian pengalaman keberhasilan atau penguasaan (Bandura dikutip Feist \& Feist, 2008). Dalam hal ini, KK tidak mendapatkan mastery experience.

Pada penelitian selanjutnya diharapkan mengambil populasi yang lebih besar agar data lebih kaya, melibatkan observasi praktik mengajar SRL di kelas pada sebelum dan sesudah pelatihan, menggunakan alat ukur seperti inventory list atau self-report yang diisi guru dan siswa untuk melihat bagaimana guru menilai dirinya dan siswa menilai gurunya mengenai praktik mengajar SRL guru tersebut di dalam kelas, rentang waktu pelatihan disarankan lebih panjang, jeda waktu antar satu sesi pelatihan ke sesi berikutnya juga disarankan lebih lama, menggabungkan metode penelitian dengan metode wawancara dan observasi (mixed method) sehingga diperoleh gambaran partisipan yang lebih rinci, serta pengambilan data kontrol dan analisis data sebaiknya juga mempertimbangkan teori-teori perkembangan, pola asuh serta urutan lahir.

\section{Ucapan terima kasih}

Terima kasih kami ucapkan kepada SD X yang mengijinkan kami untuk mengambil data dan melaksanakan pelatihan. Terima kasih juga kami ucapkan untuk seluruh partisipan penelitian yaitu para guru, serta Ibu Gina dari pihak manajemen yang sudah memberikan ijin. 


\section{REFERENSI}

Ajzen, I., \& Fishbein, M. (1980). Understanding attitudes and predicting social behavior. Englewood Cliffs, NJ: Prentice-Hall, Inc.

Azevado, R., Moos, D., Greene, J., Winters, F., \& Cromley, J. (2008). Why is externallyfacilitated learning more effective than self-regulated learning with hypermedia? Education Technology Research Development, 56, 45-72. Diunduh dari http://link.springer.com/article/10.1007\%2Fs11423-007-9067-0

Bandura, A. (1986). Social foundations of thought and action: A social cognitive theory. Prentice-Hall, Inc.

Dignath, C. (2016). Which components of teacher competence determine whether teachers enhance self-regulated learning? Predicting teachers' self-reported promotion of selfregulated learning by means of teacher beliefs,knowledge, and self-efficacy. Frontline Learning Research, 4(5), 83-105. Diunduh dari http://journals.sfu.ca/flr/index.php/journal/article/view/247/326

Endedijk, M. D., Brekelmans, M., Sleegers, P., \& Vermunt, J. D. (2015). Measuring student's self-regulated learning in professional education: Bridging the gap between event and aptitude measurement. Qual Quant. doi: 10.1007/s11135-015-0255-4

Erdem, E. \& Demirel, O. (2007). Teacher self-efficacy belief. Social Behavior and Personality, 35(5), 573-586. doi:10.2224/sbp.2007.35.5.573

Feist, J., \& Feist, G. J. (2008). Theories of personality. Yogyakarta: Pustaka Belajar.

Kilbourne, J. \& Pipher, M. (2000). Can't buy my love: How advertising changes the way we think and feel. New York, NY: Free Press.

Lombaerts, K., De Backer, F., Engels, N., van Braak, J., \& Athanasou, J. (2009). Development of the self-regulated learning teacher belief scale. European Journal of Psychology of Education, 24(1), 79-96. doi:10.1007/BF0317347

McCarthy, B. (2012). The learning cycle, the 21st century and millenial learners. Wauconda, IL: About Learning.

Olsen, N. R., Bradley, P., Espehaug, B., Nortvedt, M. W., Lygren, H., Frisk, B., Bjordal, J. M. (2015). Impact of a multifaceted and clinically integrated training program in evidencebased practice on knowledge, skills, beliefs and behavior among clinical instructors in physiotherapy: A non-randomized controlled study. Plos One, 10(4), 1-17. doi: 10.1371/journal.pone.0124332

Postmus, J. L., McMahon, S., Warrener, C., \& Macri, L. (2013). Factors that influence attitudes, beliefs, and behaviors of students toward survivors of violence. Journal of Social Work Education, $\quad 47(2), \quad 303-319 . \quad$ Diunduh dari http://www.tandfonline.com/doi/abs/10.5175/JSWE.2011.200900122

Sablonniere, R. D. L., Taylor, D. M., \& Sadykova, N. (2009). Challenges of applying a studentcentered approach to learning in the context of education in Kyrgyztan. International Journal of Educational Development, 1142, 1-7. doi: 10.1016/j.ijejudev.2009.01.001

Schunk, D. H., \& Zimmerman, B. J. (2012). Motivation and self-regulated learning: Theory, research, and application. New York, NY: Routledge.

Schwarzer, R., Schmitz, G. S., Daytner, G. (1999). Teacher self-efficacy. Diunduh dari http://userpage.fu-berlin.de/ health/teacher_se.htm Vallet, 2005

Sekolah HighScope Indonesia. (2012). Elementary (K-5) school handbook. Jakarta: HighScope Indonesia Institute.

Smith, D. B., \& Day, N. E. (2015). Family development credential training impact on selfefficacy beliefs of human service workers. Journal of Health and Human Services Administration, $\quad 38(3), \quad 317-349 . \quad$ Diunduh http:/le- 
resources.perpusnas.go.id:2071/docview/1770508391/fulltextPDF/5EA476ACA4FD452 $\mathrm{BPQ} / 1$ ?accountid=25704

Spruce, R., \& Bol, L. (2015). Teacher beliefs, knowledge, and practice of self-regulated learning. Metacognition Learning, 10, 245-277. Diunduh dari https://www.researchgate.net/publication/279459880_Teacher_beliefs_knowledge_and_p ractice_of_self-regulated_learning

Zumbrunn, S., Tadlock, J., \& Roberts, E. D. (2011). Encouraging self-regulated learning in the classroom: A review of the literature. Richmond, VA: Metropolitan Educational Research Consortium. Diunduh dari http://www.selfregulation.ca/uploads/5/6/2/6/56264915/encouraging_self_regulated_learning_in_the_cla ssroom.pdf 